\title{
Homograft Aortic Root Replacement with Saphenous Vein Graft Hemi-Cabrol for Prosthetic Aortic Valve Endocarditis
}

\author{
loannis Dimarakis, MD, PhD, MRCS*, Wilfred J. Wooldridge, FRCA, Isaac Kadir, FRCS (C-Th) \\ Department of Cardiothoracic Surgery, Wythenshawe Hospital, Manchester, UK
}

\begin{abstract}
A 44-year-old female presented with prosthetic valve endocarditis with periannular abscess involving the left coronary ostium. We describe cryopreserved aortic homograft root replacement with hemi-Cabrol reimplantation of the left coronary ostium using the long saphenous vein.

Copyright $\odot 2015$ Science International Corp.
\end{abstract}

\section{Key Words}

Prosthetic valve endocarditis - Aortic root abscess • Re-operative surgery $\bullet$ Homograft $•$ Cabrol

\section{Introduction}

Reoperation for prosthetic aortic valve endocarditis remains associated with high perioperative mortality [1]. Varying degrees of tissue destruction and anatomical distortion are typical and therefore must be considered during preoperative surgical planning. We report a case of prosthetic aortic valve endocarditis with extensive annular abscess formation that did necessitate modification of our initial strategy.

\section{Case Presentation}

A 44-year-old female presented to her local district general hospital with clinical symptoms and signs of sepsis including malaise, rigors, pyrexia, and raised

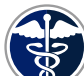

Fax +1 2037853552

E-Mail: aorta@scienceinternational.org

http://aorta.scienceinternational.org

\author{
(C) 2015 AORTA \\ Published by Science International Corp. \\ ISSN 2325-4637 \\ Accessible online at: \\ http://aorta.scienceinternational.org
}

inflammatory markers. In the fortnight preceding this admission she had also been briefly admitted on two occasions with generalized malaise, low-grade pyrexia, and a documented neurological event that completely resolved. On both occasions, investigations were inconclusive and the treating physicians discharged the patient.

She had undergone aortic valvotomy at the age of 12 as a result of congenital bicuspid aortic valve, going on to have a mechanical aortic valve replacement at the age of 34 for severe aortic stenosis.

Medical history included severe asthma for which on three occasions she had required admission to intensive care for intubation and ventilation. She was also known to have a solitary kidney with reduced glomerular filtration rate. She was immobilized in a wheel chair after developing bilateral steroid-related calcaneal avascular necrosis.

Investigations confirmed the diagnosis of aortic prosthetic valve endocarditis and, having been declined surgery by her local cardiac surgical department, she was referred to our center for further management. Blood cultures from the referring hospital as well as our unit were positive for Staphylococcus epidermidis, known to cause biofilms on prosthetic material within the bloodstream. Sensitivity-guided antibiotic treatment was commenced with intravenous vancomycin, rifampicin, and ceftazidime. Transesophageal echocardiography showed a circumferential aortic root abscess with large

* Corresponding Author:

loannis Dimarakis, MD, PhD, MRCS

Department of Cardiothoracic Surgery

Southmoor Road, Wythenshawe, Greater Manchester, M23 9LT, UK

Tel: +44 161291 2565, Fax: +44 161291 2685, E-mail: jdimarakis@nhs.net 


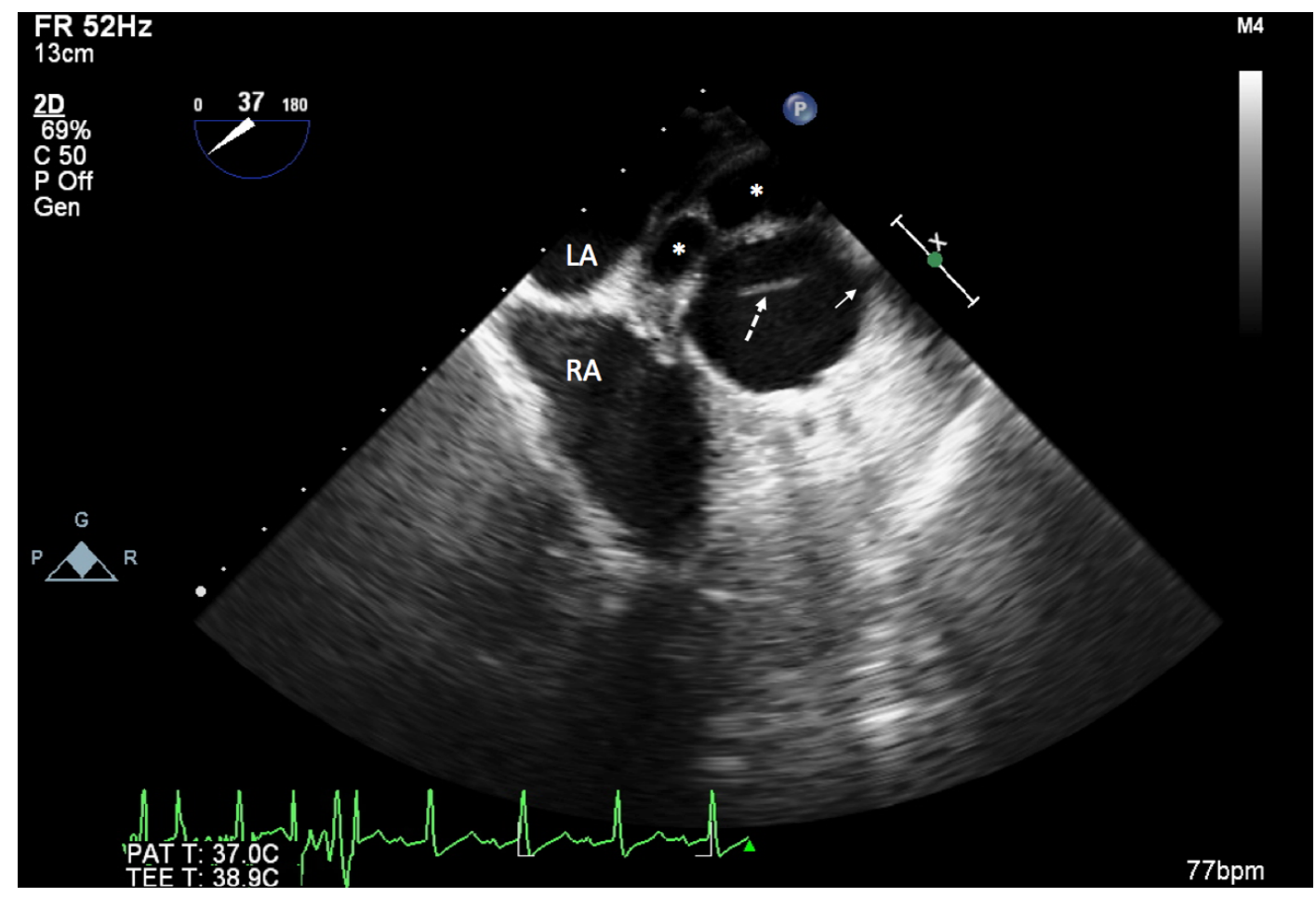

Figure 1. Modified transverse aortic valve view on intraoperative 2D transesophageal echocardiography. The two asterisks $\left({ }^{*}\right)$ depict aortic root abscess cavities. The dashed arrow demonstrates the in situ bileaflet mechanical aortic prosthesis. The solid arrow shows the ostium of the left coronary artery. LA, left atrium; RA, right atrium.

prosthetic valve vegetation. Computed tomography demonstrated solitary hepatic and splenic lesions compatible with established infarcts.

Following multidisciplinary discussion (microbiology, cardiology, and cardiac surgery teams) and discussion with the patient, urgent surgery as a second redo procedure was decided upon, as she remained unwell and in worsening heart failure. In view of the patient's young age and clinical findings, a cryopreserved aortic homograft was ordered from the national tissue bank with size matching based on knowledge of the in situ prosthesis dimensions and preoperative echocardiographic annulus measurements.

Standard anaesthesia technique was used with single lumen endotracheal intubation and routine hemodynamic/monitoring lines. Intraoperative transesophageal echocardiogram confirmed the presence of a large vegetation prolapsing into the left ventricular outflow tract and evidence of a posterior paravalvular leak into a large root abscess cavity (Figure 1 and Figure 2). Good left ventricular function was documented.

Following an uneventful redo median sternotomy, cardiopulmonary bypass was started between a right axillary arterial and a percutaneously inserted right femoral venous cannula. The pericardial space was dissected to allow insertion of right superior pulmonary vein and retrograde cardioplegia cannulae. A large root abscess was found centered over the commissure between the left and noncoronary sinuses extending inferiorly into the roof of the mitral valve.

The in-situ mechanical prosthesis was excised and all infected and/or necrotic tissue was radically resected and sent for microbiology culture. Due to the anatomical extent of the periannular abscess following debridement, an aortic homograft root replacement was carried out with interrupted polypropylene non-pledgeted sutures. The left coronary button tissue was friable and a hemi-Cabrol anastomosis with a segment of long saphenous vein was carried out (Figure 3). The right coronary button was anastomosed in a routine fashion. As the ascending aorta was 


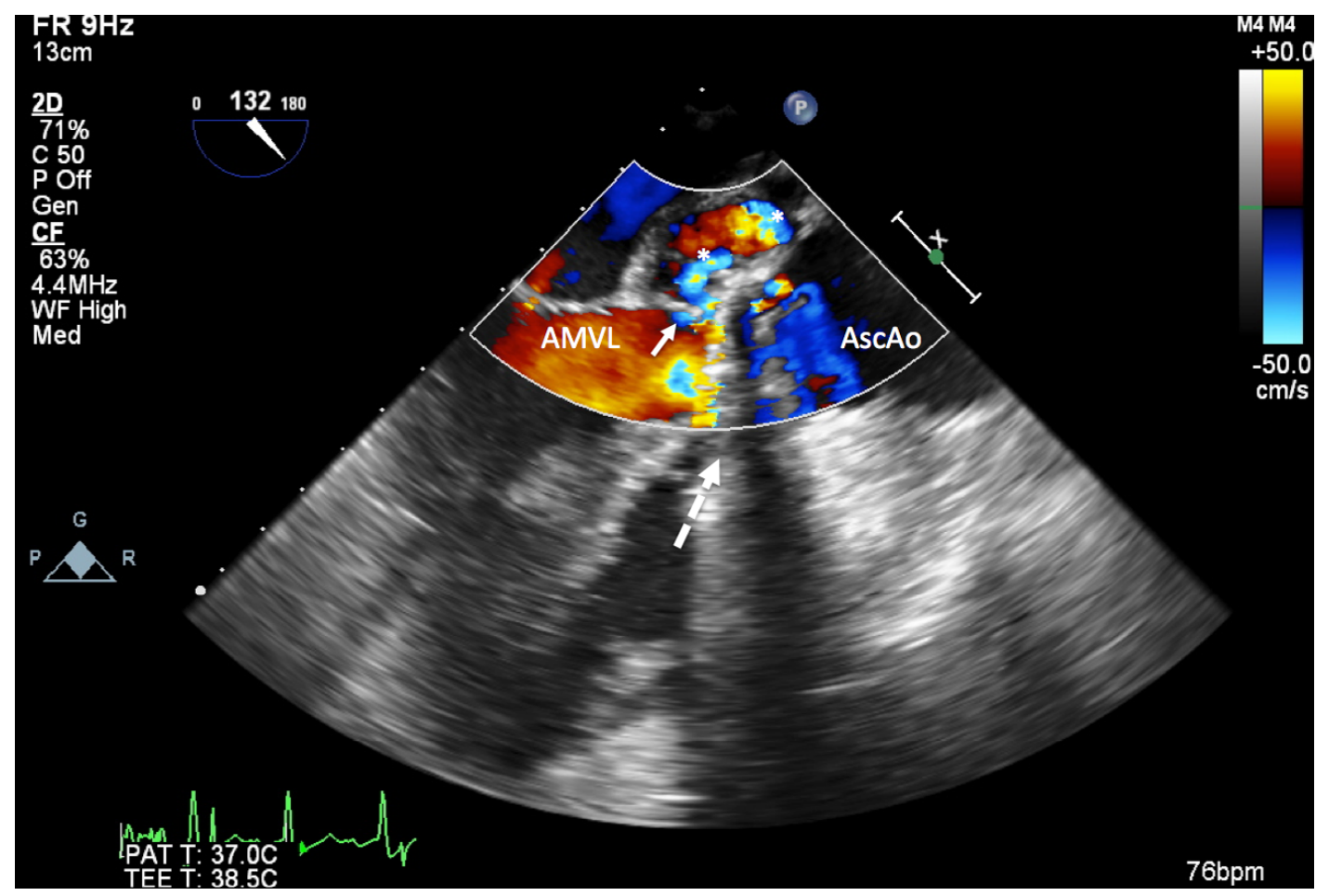

Figure 2. Color flow Doppler long-axis aortic valve view on intraoperative $2 \mathrm{D}$ transesophageal echocardiography. The solid arrow shows the paravalvular communication with the aortic root abscess cavities $\left({ }^{*}\right)$. The dashed arrow demonstrates the in situ bileaflet mechanical aortic prosthesis. AMVL, anterior mitral valve leaflet; AscAo, ascending aorta.

aneurysmal. the aorta was excised up to the innominate artery and aortic continuity was achieved with a Hemashield graft (Boston Scientific Corporation, Natick, MA). The anastomosis to the distal ascending aortic stump was carried out under a brief period of lower body circulatory arrest and antegrade selective cerebral perfusion. The patient was separated from cardiopulmonary bypass with no difficulties.

She developed respiratory failure postoperatively and needed tracheostomy but recovered gradually. She was discharged following completion of eight weeks of intravenous antibiotics as advised by our clinical infection specialists.

\section{Discussion}

Data from the International Collaboration on Endocarditis-Prospective Cohort Study demonstrated that prosthetic valve endocarditis accounted for over $20 \%$ of all enrolled cases, with persistent bacteremia, heart failure, intracardiac abscess, and stroke being the strongest predictors of mortality [2]. It further highlighted that in comparison to native valve endocarditis, the incidence of intracardiac abscesses was significantly greater in prosthetic valve endocarditis.

Recommendations for indications and timing of

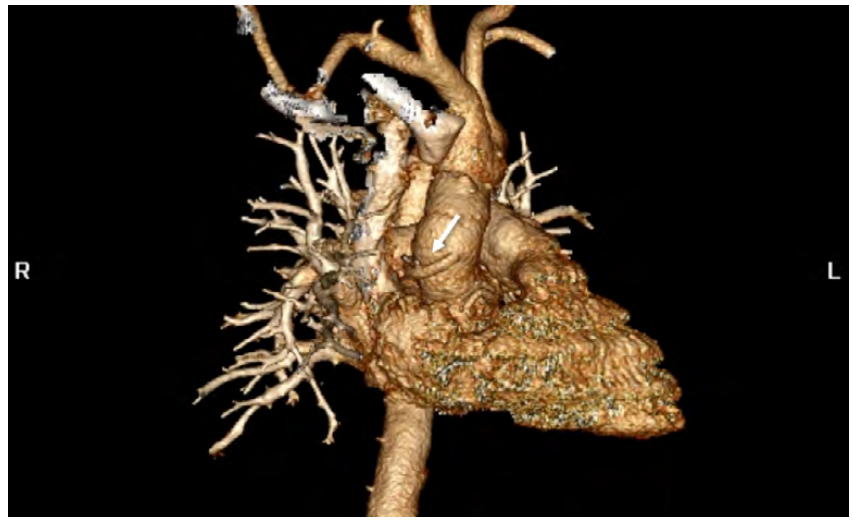

Figure 3. Three-dimensional computed tomographic reconstruction: The arrow shows the saphenous vein hemi-Cabrol graft anastomosed to the anterior surface of the homograft. 
surgery in prosthetic valve infective endocarditis have been recently published [3]. Mainstay of surgical treatment incorporates total removal of infected tissues and restoration of cardiac morphology alongside sensitivity-guided intravenous antimicrobial treatment. The need for radical debridement of all infected and/or necrotic tissue encountered intraoperatively has been highlighted by a number of groups $[4,5]$. No randomized controlled trial data exist in the literature regarding the use of conventional prostheses versus homograft in such cases. Key features of homograft implantation include pliability in anatomically distorted annular anatomy in addition to reduction of risk of recurrent infection. Notwithstanding, conventional prostheses have also been demonstrated to provide excellent results [6].

Coronary artery ostial involvement is also more common in the setting of prosthetic valve endocarditis [7]. In the described case we proceeded with a hemi-Cabrol technique for the reimplantation of the left coronary ostium using a segment of reversed long saphenous vein. Once again this was done in order to minimize the amount of foreign material sitting in the exteriorized abscess cavity.

The extent of debridement in our experience will dictate the choice of surgical repair. In cases with extensive or circumferential annular abscess, aorto-mitral curtain involvement, and fistulae we opt for cryopreserved aortic homograft root replacement if available. We acknowledge the fact of structural deterioration especially in younger patients [8] and we do convey this to patients during the informed consent process.

It is worth mentioning that the patient described exhibited phenotypic features of Turner syndrome, including short stature, webbed neck, low posterior hairline, broad chest, congenital aortic stenosis, and solitary kidney. Unfortunately she declined to undergo cytogenetic evaluation.

In conclusion, aortic prosthetic valve endocarditis remains a daunting surgical entity that requires aggressive patient-tailored management. As the complexity of surgical repair may demand use of aortic homograft root reconstruction with or without coronary anatomy restoration, knowledge of operative alternatives is essential to achieve a satisfactory outcome.

\section{Conflict of Interest}

The authors have no conflict of interest relevant to this publication.

\section{Comment on this Article or Ask a Question}

\section{References}

1. Leontyev $S$, Borger MA, Modi P, Lehmann $S$, Seeburger J, Walther T, et al. Redo aortic valve surgery: Influence of prosthetic valve endocarditis on outcomes. J Thorac Cardiovasc Surg. 2011;142:99-105. DOI: 10.1016/j.jtcvs.2010.08.042

2. Wang A, Athan E, Pappas PA, Fowler VG, Jr., Olaison L, Pare C, et al. Contemporary clinical profile and outcome of prosthetic valve endocarditis. JAMA. 2007;297:1354-1361. DOI: 10.1001/jama.297.12.1354

3. Tornos P, Gonzalez-Alujas T, Thuny F, Habib G. Infective endocarditis: the European viewpoint. Curr Probl Cardiol. 2011;36:175222. DOI: 10.1016/j.cpcardiol.2011.03.004

4. Sabik JF, Lytle BW, Blackstone EH, Marullo AG, Pettersson GB, Cosgrove DM. Aortic root replacement with cryopreserved allograft for prosthetic valve endocarditis. Ann Thorac Surg. 2002;74:650-659. DOI: 10.1016/S0003-4975(02)03779-7
5. Yankah $A C$, Pasic $M$, Klose $H$, Siniawski $H$, Weng $Y$, Hetzer R. Homograft reconstruction of the aortic root for endocarditis with periannular abscess: a 17-year study. Eur J Cardiothorac Surg. 2005;28:69-75. DOI: 10.1016/j.ejcts.2005.03.017

6. Hagl C, Galla JD, Lansman SL, Fink D, Bodian CA, Spielvogel D, et al. Replacing the ascending aorta and aortic valve for acute prosthetic valve endocarditis: is using prosthetic material contraindicated? Ann Thorac Surg. 2002;74:S1781-5. DOI: 10.1016/S0003-4975(02)04142-5

7. Leontyev S, Borger MA, Modi P, Lehmann $S$, Seeburger J, Doenst T, et al. Surgical management of aortic root abscess: a 13-year experience in 172 patients with 100\% follow-up. J Thorac Cardiovasc Surg. 2012;143:332-7. DOI: 10.1016/j. jtcvs.2010.10.064

8. Takkenberg JJ, Klieverik LM, Bekkers JA,
Kappetein AP, Roos JW, Eijkemans MJ, et al. Allografts for aortic valve or root replacement: insights from an 18-year single-center prospective follow-up study. Eur J Cardiothorac Surg. 2007;31:851-9. DOI: 10.1016/j.ejcts.2007.02.009

Cite this article as: Dimarakis I, WJ Wilfred, Kadir I. Homograft Aortic Root Replacement with Saphenous Vein Graft Hemi-Cabrol for Prosthetic Aortic Valve Endocarditis. AORTA 2015;3(2):8185. DOI: http://dx.doi.org/10.12945/j. aorta.2015.14-047 


\section{EDITOR'S QUESTIONS}

\section{How will you follow the saphenous vein graft?}

Our imaging follow up includes early postoperative and subsequently annual high-resolution cardiac computed tomography or magnetic resonance aortography looking specifically at the vein graft. In addition, annual transthoracic echocardiographic surveillance is planned to assess and monitor homograft function as well as biventricular function, a surrogate marker of vein graft disease. We will do this for annually for 5 years and then carry on indefinitely at increasing intervals or as symptoms dictate. In addition, secondary prevention of vein graft disease in the form of high dose statins, ACE inhibitor, aspirin and lifestyle modification has been advised.

2. Did you consider routing the saphenous vein graft posteriorly, to the right side of the graft?

This is exactly what we have done. 